\title{
In Vitro fertilization (IVF) treatments in Maccabi Healthcare Services 2007-2014
}

\author{
Shahar Kol ${ }^{*}$, Lucia Bergovoy Yellin², Yaakov Segal ${ }^{1}$ and Avi Porath ${ }^{1}$
}

\begin{abstract}
Background: Israel reports the world's highest IVF cycles per capita. However, clinical outcome data of these treatments are scarce. In a previous publication, we summarized IVF results among Maccabi Healthcare Services members for the years 2007-2010. The main findings included an increase in mean patients' age over the period studied, a $50 \%$ increase in cycle numbers during this time, and a decrease in success rate (live birth) from $18.8 \%$ in 2007 to $14.8 \%$ in 2010. The purpose of the current publication is to summarize IVF outcome for the years 2011-2014, and to explore possible changes in the trends we reported previously.

Methods: IVF and live births data were collected from Maccabi Healthcare Services' fertility treatments registry. Analyses were conducted by treatment year and patients' age at the initiation of treatment cycles. Autologous cycles, were included (ovum donation cycles and frozen-thaw cycles were excluded). A successful cycle was defined if a live birth was recorded within 10 months of its initiation.

Results: In accordance with previous data for the years 2007-2010, mean patients' age continued to rise (from 36.2 in 2011 to 37.1 in 2014). In contrast to previous years, during which a continued increase in treatment cycles was recorded, we found that treatment number decreased from a peak of 9,751 in 2011 to 8,623 in 2014. Contrary to that trend, the number of patients over 40 years of age increased from 3,204 in 2011 to 3,648 in 2014. Success rate fluctuated between $14.4 \%$ in 2014 to $16.4 \%$ in 2013. The majority (78\%) of treatment cycles were conducted in four private medical centers.

Conclusions: The decrease in treatment cycles in recent years notwithstanding, Israel is still leading the world with IVF treatments relative to population. Success rate is relatively low compared to international data. Given the steady increase in patients' mean age, and particularly, the increase in patients over 40 years of age, we maintain that the low success rate reflects a growing number of treatments that a priori have a low chance of success.
\end{abstract}

Keywords: In-vitro fertilization, Assisted reproductive technology, Maccabi Healthcare Services, Israel, Infertility registry

\section{Background}

The number of IVF cycles performed in Israel (relative to population size) is the highest in the world [1]. The main reason is the unprecedented Israeli IVF health basket, which provides practically unlimited IVF treatments to eligible infertility patients who are under 45 years old and have no more than two children, including single mothers [2]. While this policy was challenged by professional organizations, it seems that for many years politicians were reluctant to limit IVF treatments. Moreover, the Ministry of Health as the regulatory body stated in

\footnotetext{
* Correspondence: kol_sh@mac.org.il

${ }^{1}$ Maccabi Healthcare Services, Tel Aviv, Israel

Full list of author information is available at the end of the article
}

2014 that given medical considerations, IVF treatment could be regarded as first line of treatment for patients over 39 years of age [3].. When professional considerations to stop treatments before the 45 year age limit were challenged in court [4], the judge decided in favor of the patient, stating that the maximal age for treatment (45) was decided based on medical considerations and the current medical literature. Of note, the pertinent professional body (The Israel Fertility Association) recommended lowering the upper age limit for IVF treatments.

The relative low "out of pocket" cost, and the high availability of IVF services in Israel [4] contributed to the popularity of IVF treatments. Currently, IVF services 
Table 1 Number of IVF treatments performed, number of live births achieved from these treatments, and success rate by year (2007-2014)

\begin{tabular}{|c|c|c|c|c|c|c|}
\hline Year & Number of patients & Number of treatments & Number of live births & Cycles/patient & Live birth/cycle & Live birth/patient \\
\hline 2007 & 4,061 & 6,242 & 1,182 & 1.54 & $18.9 \%$ & $29.1 \%$ \\
\hline 2008 & 4,410 & 7,041 & 1,295 & 1.60 & $18.4 \%$ & $29.4 \%$ \\
\hline 2009 & 4,867 & 8,336 & 1,356 & 1.71 & $16.3 \%$ & $27.9 \%$ \\
\hline 2010 & 5,282 & 9,297 & 1,384 & 1.76 & $14.9 \%$ & $26.2 \%$ \\
\hline 2011 & 5,479 & 9,751 & 1,429 & 1.78 & $14.7 \%$ & $27.9 \%$ \\
\hline 2012 & 5,375 & 9,314 & 1,438 & 1.73 & $15.4 \%$ & $26.7 \%$ \\
\hline 2013 & 5,360 & 8,455 & 1,386 & 1.58 & $16.4 \%$ & $25.9 \%$ \\
\hline 2014 & 5,577 & 8,623 & 1,238 & 1.55 & $14.4 \%$ & $22.2 \%$ \\
\hline Total & 40,411 & 67,059 & 10,708 & 1.66 & $16.0 \%$ & $26.5 \%$ \\
\hline
\end{tabular}

are available in all Israeli public medical centers (excluding Zefat, the 3 Nazareth medical centers and Eilat), in addition to four IVF units in private medical centers (Elisha, HMC, Assuta Tel Aviv and Assuta Rishon LeZion).

IVF activity is monitored by a long list of national and international organizations, most notably the Society for Assisted Reproductive Technologies (SART) [5] and the Centers for Disease Control and Prevention (CDC) (http://www.cdc.gov/art/reports/) in the United States, and the European Society for Human Reproduction and Embryology (ESHRE) in Europe [6]. Currently, an effort to establish an Israeli IVF registry is underway, though periodic comprehensive reports are not yet available. Professor Liat Lerner-Geva presented preliminary data on clinical pregnancy rate at the 2015 annual meeting of the Israel Fertility Association. The Ministry of Health publishes limited retrospective annual reports [7]. According to these reports available from 2000 to 2013, live birth rate per treatment cycles ranges between 14.9$17.2 \%$. These results fall significantly short of the reported live birth rate per treatment cycles as published by the above registries.

Previously, we summarized IVF results among Maccabi members for the years 2007-2010 [8]. The main findings included an increase in mean patients' age over the period examined, a $50 \%$ increase in cycle numbers during this period, and a decrease in success rate (live birth) from $18.8 \%$ in 2007 to $14.8 \%$ in 2010 . The purpose of the current communication is to summarize the IVF outcomes for the years 2011-2014, to explore possible changes in the trends we reported previously, while deepening the analysis and exploring the policy implications of the findings.

\section{Methods}

Maccabi Healthcare Services is the second largest Health Maintenance Organization (HMO) in Israel covering 433,711 women in fertility ages (15-45) according to the
National Insurance Institute report of November 2014 [9], or $25.7 \%$ of the total fertility age population (1,687,873 women).

In an attempt to gain further insight on IVF activity in Israel, we analyzed data generated from the Maccabi Healthcare Services fertility treatment registry. The

Table 2 Number of IVF treatments and success rate by year (2011-2014) and age group

\begin{tabular}{|c|c|c|c|c|c|}
\hline Year & $\begin{array}{l}\text { Age } \\
\text { group }\end{array}$ & $\begin{array}{l}\text { Number of } \\
\text { treatments }\end{array}$ & $\begin{array}{l}\text { Number of } \\
\text { live births }\end{array}$ & $\begin{array}{l}\text { Success } \\
\text { rate [\%] }\end{array}$ & $\begin{array}{l}\text { Distribution } \\
\text { by age }\end{array}$ \\
\hline \multirow[t]{6}{*}{2011} & 15-19 & 4 & 0 & 0 & $0.0 \%$ \\
\hline & $20-24$ & 226 & 56 & 24.8 & $2.3 \%$ \\
\hline & $25-29$ & 1,086 & 277 & 25.5 & $11.2 \%$ \\
\hline & $30-34$ & 2,104 & 449 & 21.3 & $21.7 \%$ \\
\hline & $35-39$ & 3,082 & 479 & 15.5 & $31.8 \%$ \\
\hline & $40-45$ & 3,204 & 168 & 5.2 & $33.0 \%$ \\
\hline \multirow[t]{6}{*}{2012} & 15-19 & 7 & 2 & 28.6 & $0.1 \%$ \\
\hline & $20-24$ & 187 & 49 & 26.2 & $2.0 \%$ \\
\hline & $25-29$ & 947 & 273 & 28.8 & $10.2 \%$ \\
\hline & $30-34$ & 1,905 & 437 & 22.9 & $20.5 \%$ \\
\hline & $35-39$ & 2,772 & 468 & 16.9 & $29.9 \%$ \\
\hline & $40-45$ & 3,466 & 209 & 6.0 & $37.3 \%$ \\
\hline \multirow[t]{6}{*}{2013} & 15-19 & 4 & 0 & 0.0 & $0.0 \%$ \\
\hline & $20-24$ & 188 & 45 & 23.9 & $2.2 \%$ \\
\hline & $25-29$ & 832 & 235 & 28.2 & $9.9 \%$ \\
\hline & $30-34$ & 1,657 & 452 & 27.3 & $19.7 \%$ \\
\hline & $35-39$ & 2,470 & 425 & 17.2 & $29.3 \%$ \\
\hline & $40-45$ & 3,271 & 228 & 7.0 & $38.8 \%$ \\
\hline \multirow[t]{6}{*}{2014} & $15-19$ & 4 & 0 & 0.0 & $0.0 \%$ \\
\hline & $20-24$ & 184 & 52 & 28.3 & $2.1 \%$ \\
\hline & $25-29$ & 804 & 203 & 25.2 & $9.4 \%$ \\
\hline & $30-34$ & 1,547 & 380 & 24.6 & $18.0 \%$ \\
\hline & $35-39$ & 2,411 & 386 & 16.0 & $28.0 \%$ \\
\hline & $40-45$ & 3,648 & 217 & 5.9 & $42.4 \%$ \\
\hline
\end{tabular}




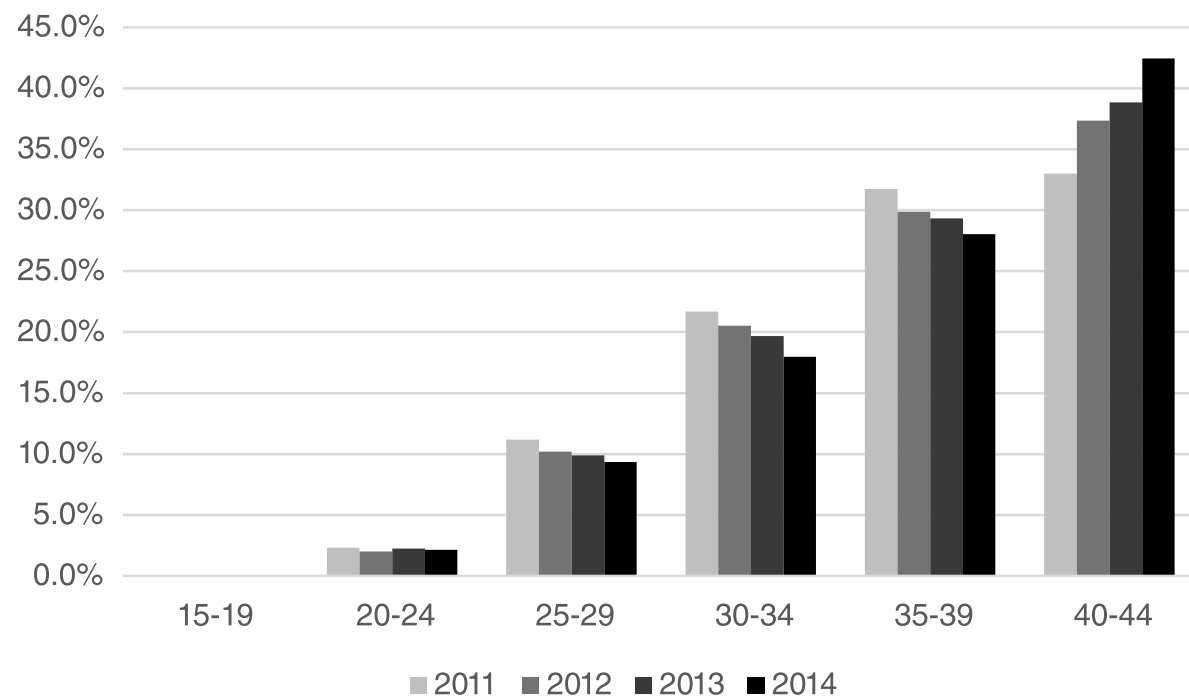

Fig. 1 Age distribution of cycles by year, 2011-2014

responsible HMO reimburses all IVF treatments for Israeli citizens (in public and private medical centers alike); therefore, reliable information is gathered on the number of cycles performed in all IVF units.

All IVF treatments of Maccabi members are routinely registered as part of the reimbursement system that serves the financial infrastructure to all treatments performed. Live birth is reimbursed by the National Insurance Institute of Israel, and therefore is not directly reported to the pertinent HMO. However, as a default, the newborn is registered to his/her mother's HMO, generating a significant financial movement for the HMO (one more member). A cross-match between these two financial movements (paying the medical center for IVF and adding a new member to the HMO) can yield a good estimate (though not perfect) of live birth rate post IVF, if a live birth occurred within 10 months from the IVF treatment.

In the current publication we included "fresh" cycles, defined as ovarian stimulation + oocyte retrieval ("phase 1") followed by fertilization and embryo transfer 2 6 days after oocyte retrieval ("phase 2"). We collected data on patients' age on the day of IVF treatment, the specific medical center where treatment was given, and number of cycles performed in each medical center.

Table 3 Mean age of IVF patients by medical center type (public/private), 2011-2014

\begin{tabular}{lcl}
\hline Medical center type & Mean age & Number of treatments \\
\hline Public & 35.46 & 16,004 \\
Private & 36.50 & 51,055 \\
Total & 36.25 & 67,059 \\
\hline
\end{tabular}

Table 4 Number of IVF treatments and success rates for women $\geq 40$ year old age group, by year (2011-204) and age

\begin{tabular}{|c|c|c|c|c|}
\hline Year & Age & $\begin{array}{l}\text { Number of } \\
\text { treatments }\end{array}$ & $\begin{array}{l}\text { Number of } \\
\text { live births }\end{array}$ & $\begin{array}{l}\text { Success } \\
\text { rate [\%] }\end{array}$ \\
\hline \multirow[t]{6}{*}{2011} & Total & 3,204 & 168 & 5.2 \\
\hline & 40 & 660 & 68 & 10.3 \\
\hline & 41 & 736 & 38 & 5.2 \\
\hline & 42 & 716 & 31 & 4.3 \\
\hline & 43 & 555 & 21 & 3.8 \\
\hline & 44 & 537 & 10 & 1.9 \\
\hline \multirow[t]{6}{*}{2012} & Total & 3,466 & 209 & 6.0 \\
\hline & 40 & 716 & 89 & 12.4 \\
\hline & 41 & 789 & 52 & 6.6 \\
\hline & 42 & 741 & 37 & 5.0 \\
\hline & 43 & 649 & 21 & 3.2 \\
\hline & 44 & 571 & 10 & 1.8 \\
\hline \multirow[t]{6}{*}{2013} & Total & 3,271 & 228 & 7.0 \\
\hline & 40 & 635 & 74 & 11.7 \\
\hline & 41 & 757 & 72 & 9.5 \\
\hline & 42 & 736 & 57 & 7.7 \\
\hline & 43 & 599 & 20 & 3.3 \\
\hline & 44 & 544 & 5 & 0.9 \\
\hline \multirow[t]{6}{*}{2014} & Total & 3,648 & 217 & 5.9 \\
\hline & 40 & 781 & 77 & 9.9 \\
\hline & 41 & 855 & 59 & 6.9 \\
\hline & 42 & 759 & 43 & 5.7 \\
\hline & 43 & 702 & 28 & 4.0 \\
\hline & 44 & 551 & 10 & 1.8 \\
\hline
\end{tabular}


Data for 2011-2014 were collected and summarized in late September 2015; therefore, we assume that all pregnancies achieved in 2014 have ended by that time.

\section{Results}

Treatments and live birth rate

The 8 years surveyed can be divided into 2 periods: A steady increase in the number of treatments from 2007 (6,242 treatments) to a peak in 2011 (9,751 treatments), and a moderate decrease in treatments thereafter. Live birth rate decreased from $18.9 \%$ in 2007 to $14.4 \%$ in 2014 (Table 1).

\section{Treatments and live birth rate according to patients' age groups}

From 2011 to 2014, a steady decrease was noted in the treatments performed in the younger age groups (25-39), with a parallel steady increase in the $40-45$ age group. A

Table 5 Number of IVF treatments and success rate, by year (2011-2012) and medical center (only medical centers with $\geq 100$ cycles per given year were included)

\begin{tabular}{|c|c|c|c|c|}
\hline Year & Medical center ${ }^{a}$ & $\begin{array}{l}\text { Number of } \\
\text { treatments }\end{array}$ & $\begin{array}{l}\text { Number of } \\
\text { live births }\end{array}$ & Success [\%] \\
\hline \multirow[t]{12}{*}{2011} & Total & 9,751 & 1,429 & 14.7 \\
\hline & A & 914 & 93 & 10.2 \\
\hline & B & 561 & 40 & 7.1 \\
\hline & C & 673 & 114 & 16.9 \\
\hline & $\mathrm{D}$ & 1,958 & 387 & 19.8 \\
\hline & E & 3,908 & 502 & 12.8 \\
\hline & $\mathrm{F}$ & 223 & 49 & 22.0 \\
\hline & G & 120 & 24 & 20.0 \\
\hline & $\mathrm{H}$ & 307 & 48 & 15.6 \\
\hline & I & 161 & 40 & 24.8 \\
\hline & J & 303 & 18 & 5.9 \\
\hline & K & 170 & 37 & 21.8 \\
\hline \multirow[t]{12}{*}{2012} & Total & 9,314 & 1,438 & 15.4 \\
\hline & A & 889 & 101 & 11.4 \\
\hline & B & 420 & 44 & 10.5 \\
\hline & C & 637 & 112 & 17.6 \\
\hline & $\mathrm{D}$ & 1,988 & 371 & 18.7 \\
\hline & E & 3,574 & 522 & 14.6 \\
\hline & $\mathrm{F}$ & 248 & 42 & 16.9 \\
\hline & G & 109 & 25 & 22.9 \\
\hline & $\mathrm{H}$ & 321 & 48 & 15.0 \\
\hline & । & 152 & 34 & 22.4 \\
\hline & J & 346 & 37 & 10.7 \\
\hline & K & 189 & 28 & 14.8 \\
\hline
\end{tabular}

${ }^{a}$ Medical center: in order to protect the confidential information, the names of the medical centers were recoded into random letters sharp decrease in live birth was noted for patients over 40 years of age (Table 2, Fig. 1).

\section{Mean patients' age}

A steady increase in patients' mean age was documented from 2007 (35.1) to 2014 (37.1).

\section{Mean patients' age by type of medical center}

From 2007 to 2014, 16,004 and 51,055 treatments were performed in public and private medical centers, respectively. Patients' mean age was 35.5 and 36.5 in public and private medical centers, respectively (Table 3 ).

\section{Detailed outcome for the $\mathbf{4 0 - 4 5}$ age group}

In all the years surveyed, a steady decrease in live birth rate was noted from age 40 to 44 . Two thousand two

Table 6 Number of IVF treatments and success rate, by year (2013-2014) and medical center (only medical centers with $\geq 100$ cycles per given year were included)

\begin{tabular}{|c|c|c|c|c|}
\hline Year & Medical center ${ }^{a}$ & $\begin{array}{l}\text { Number of } \\
\text { treatments }\end{array}$ & $\begin{array}{l}\text { Number of } \\
\text { live births }\end{array}$ & Success [\%] \\
\hline \multirow[t]{13}{*}{2013} & Total & 8,455 & 1,386 & 16.4 \\
\hline & A & 809 & 123 & 15.2 \\
\hline & B & 250 & 29 & 11.6 \\
\hline & C & 448 & 94 & 21.0 \\
\hline & D & 1,851 & 347 & 18.7 \\
\hline & E & 3,262 & 505 & 15.5 \\
\hline & $\mathrm{F}$ & 231 & 40 & 17.3 \\
\hline & G & 105 & 21 & 20.0 \\
\hline & $\mathrm{H}$ & 291 & 53 & 18.2 \\
\hline & I & 156 & 27 & 17.3 \\
\hline & J & 290 & 40 & 13.8 \\
\hline & K & 184 & 21 & 11.4 \\
\hline & L & 149 & 22 & 14.8 \\
\hline \multirow[t]{13}{*}{2014} & Total & 8,623 & 1,238 & 14.4 \\
\hline & A & 1,136 & 176 & 15.5 \\
\hline & B & 268 & 27 & 10.1 \\
\hline & C & 459 & 75 & 16.3 \\
\hline & D & 1,957 & 352 & 18.0 \\
\hline & E & 2,877 & 347 & 12.1 \\
\hline & $\mathrm{F}$ & 187 & 37 & 19.8 \\
\hline & G & 115 & 18 & 15.7 \\
\hline & $\mathrm{H}$ & 195 & 26 & 13.3 \\
\hline & I & 178 & 36 & 20.2 \\
\hline & J & 312 & 39 & 12.5 \\
\hline & K & 262 & 26 & 9.9 \\
\hline & L & 188 & 33 & 17.6 \\
\hline
\end{tabular}

a Medical center: in order to protect the confidential information, the names of the medical centers were recoded into random letters 
hundred and three treatments were performed in women 44 years of age from 2011 to 2014, yielding 35 live births (1.6 \%). (Table 4).

\section{Live birth rate by medical center}

Since outcome of a small number of treatments has limited statistical significance, we decided to include medical centers with $>100$ treatments per year in the analysis. There are significant changes in success rate between medical centers, and significant changes within the same medical center during the 4 years surveyed (Tables 5 and 6).

\section{Treatment distribution between public and private medical centers}

In 2007, 2,401 and 5,896 treatments were performed in public and private medical centers, respectively. Treatments in public medical centers increased marginally from 2007 to 2014 (2,618 treatments in 2014, a $9 \%$ increase). Treatments in private medical centers increased significantly from 2007 to 2014 (9,211 treatments in 2014, a 56 \% increase) (Fig. 2).

\section{Discussion and conclusions}

In the current publication, we update a previous report [8], and present an eight-year summary of IVF treatments in Maccabi Healthcare Services. Since Maccabi covers approximately $25 \%$ of the population in Israel, the data herein reliably represent the total IVF activity in Israel. We report a modest decrease in treatment cycles in recent years. The Israeli success rate is low compared to international data (http://www.cdc.gov/art/reports/) [5, 6]. Of note is a steady increase in patients' mean age, and particularly, an increase in patients greater than 40 years old.
While both live birth per cycle and per patient show a steady decline from 2007 through 2014, there is a marked decrease in the number of cycles per patient from the peak in 2011, suggesting possible changes in practice.

The health policy decisions that culminated in an unprecedented coverage of IVF treatments in Israel reflect societal and political considerations, as opposed to pure professional, evidence-based considerations. Naturally, these health policy decisions have a significant price tag. Updated in 01-September-2015, according to the Ministry of Health, an IVF treatment reimbursement costs 12,000 NIS [10]. We report herein that 2,203 treatments $(26,436,000$ NIS) were performed in women 44 years of age from 2011 to 2014, yielding 35 live births. The cost of a single live birth in that age group was 755,314 NIS (not including fertility medications supplied by Maccabi).

Previous efforts of professional organizations (most notably The Israel Fertility Association - IFA) to divert resources in a more cost effective way (i.e. ovum donation) have failed. Moreover, previous professionally based guidelines by the Ministry of Health itself to minimize futile treatments were not implemented. Although in 1999, such guidelines were adopted (http://www.ayala.org.il/?Cate goryID $=239 \&$ ArticleID $=77$ ) based on recommendations made by a professional committee, nominated by the Minister of Health, the guidelines are not currently implemented. Moreover, a timely update was not published. Given current IVF health policy, the practice of IVF shifted from a medical treatment bearing indications and contra-indications, into a social, age-related right [11]. This shift was fully endorsed by the legal system [12].

Economic costs of IVF treatments have a significant impact on the Israeli HMO's finances. A survey conducted in Maccabi in 2006 found that $5.4 \%$ of health

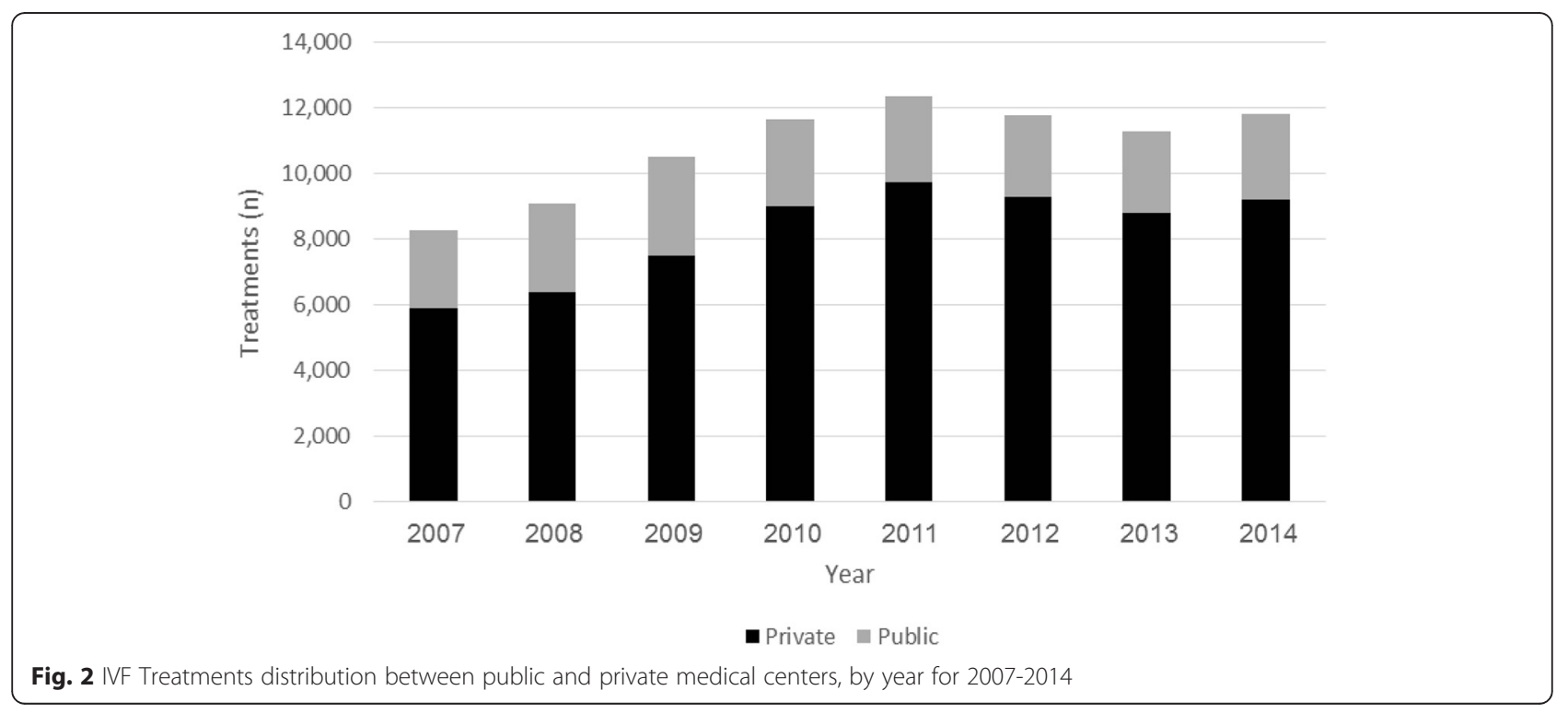


expenditures for women related to fertility treatments, more than was spent on diabetes (3.5\%) and comparable to expenditures on cardiovascular diseases (5.9\%) [13].

Naturally, IVF health policy raises significant ethical considerations. The Israel Fertility Association ethical committee published its position regarding futile IVF treatments in February 2015 [14]. The committee defined a "futile treatment" as a treatment in which the chance for live birth is $<1 \%$, and strongly denounced performing such treatment. Yet, experience shows that these considerations are defeated when challenged.

In the current publication, we detail the live birth rate achieved in different medical centers. These data must be interpreted with caution given the lack of pertinent individual clinical information i.e. indications, number of oocytes retrieved, number of embryos obtained and their quality, previous IVF failures, usage of specific technologies (pre-implantation genetic diagnosis, testicular sperm extraction, in-vitro maturation etc.). We speculate that units differ significantly as to their patients' treatment prognosis. In addition, some units impose a 44-age limit, though, as mentioned above, the IVF national health basket covers women until 45 years of age. Notably, the number of treatments performed in "Clalit" public medical centers is low; therefore, these units are underrepresented in our data.

According to the Ministry of Health, 39,174 IVF cycles were performed in 2013 [7], with a live birth rate of $15.7 \%$ (comparable to our data of $16.4 \%$ for that year). According to the CDC (http://www.cdc.gov/art/reports/) 163,212 cycles were performed in the US in the same year with a live birth rate of $33 \%$. In our opinion, this comparison highlights the fundamental problem that erodes IVF clinical outcomes in Israel: Too many cycles are performed despite a very slim chance of success.

IVF health-related policy is a subject of public and professional debate, in which the question of resource allocation should be thoroughly and openly discussed. As pointed out previously [15], the existing policy of assisted reproduction in Israel, that is, of unlimited rounds with IVF, should be further questioned and assessed. Possible conclusions of such an assessment may be that IVF treatments should cease before 45 years of age, and/or limiting treatment number for an individual patient.

\section{Competing interests}

The authors declare that they have no competing interests.

\section{Authors' contributions}

SK conceived of the study, participated in the design of the study, and wrote the manuscript draft. LBY participated in the design of the study, performed data mining, statistical analysis, and helped to draft the manuscript. YS conceived of the study, participated in the design of the study and helped to draft the manuscript. AP conceived of the study, participated in the design of the study, and helped to draft the manuscript. All authors read and approved the final manuscript.

\section{Authors' information}

Dr. Shahar Kol: North district gynecologist, director of fertility clinic at Women Heath Center in Haifa, Maccabi Healthcare Services. Director of IVF Unit at Rambam Health Care Campus, Haifa, and Assistant Professor in Ruth and Bruce Rapaport Faculty of Medicine, Technion, Haifa.

Lucia Bergovoy Yellin: Environmental Health analyst in the Department of Health Services Research at Chief Physician Office of Maccabi Healthcare Services. Also, works as an independent environmental health researcher, including consulting and mapping.

Dr. Yaakov Segal: Head of gynecologic department at Maccabi Healthcare Services Head of Women Heath Center in Hasharon County.

Prof. Avi Porath: Chief Physician of Maccabi Healthcare Services, the second largest health plan in Israel. Prof. Porath is the founder of the Israel Society of Quality in Health Care and the founder of the National Program of Quality Measures in the Community of the Ministry of Health. Prof. Porath's areas of research include quality in health care, and implementation of evidence into practice.

\section{Author details}

${ }^{1}$ Maccabi Healthcare Services, Tel Aviv, Israel. ${ }^{2}$ Department of Health Services Research at Chief Physician Office of Maccabi Healthcare Services, Tel Aviv, Israel.

Received: 17 December 2015 Accepted: 30 March 2016

Published online: 08 April 2016

\section{References}

1. Nachtigall RD. International disparities in access to infertility services. Fertil Steril. 2006;85:871-5

2. Simonstein F. IVF policies with emphasis on Israeli practices. Health Policy. 2010;97:202-8.

3. Ministry of Health. Cycles of in vitro fertilization treatment (IVF) in the healthcare service basket. Medical Administrative Circular No. 6/2014. January 2014. In Hebrew. http://www.health.gov.il/hozer/mr06_2014.pdf.

4. Collins J. An international survey of the health economics of IVF and ICSI. Hum Reprod Update. 2002;8:265-77.

5. Society for Assisted Reproductive Technologies. IVF success rates. 2013; available at: www.sart.org/Find_A_Clinic.

6. Kupka MS, Ferraretti AP, De Mouzon J, Erb K, D'Hooghe T, Castilla JA, et al. Assisted reproductive technology in Europe, 2010: results generated from European registers by ESHRE. Hum Reprod. 2014;29:2099-113.

7. In vitro fertilization in Israel 2013. Ministry of Health. In Hebrew, available at: http://www.health.gov.il/PublicationsFiles/IVF1986_2013.pdf.

8. Sella T, Segal Y, Goren I, Chodick G, Shalev V, Homburg R, Bachar R, Kol S. In-Vitro fertilization cycles and outcomes in Maccabi Healthcare Services in Israel 2007-2010. Harefuah. 2013;152:11-4.

9. Cohen R. and Rabin C. National Insurance Institute of Israel, Research and Planning Administration. Annual Survey - health maintenance organization (HMO) membership, 2014: Number 271. In Hebrew, available at: http://www.btl.gov.il/Publications/survey/Pages/seker_271.aspx.

10. State of Israel, Ministry of Health. Price list of the Ministry of Health. Update 01 September 2015. In Hebrew, available at: http://www.health.gov.il/ subjects/finance/taarifon/pages/pricelist.aspx.

11. State of Israel, Ministry of Health. IVF cycles in health basket, January 2014 In Hebrew, available at: http://www.health.gov.il/hozer/mr06_2014.pdf.

12. Work issues court in Tel Aviv, case 40040-05-14, dated 27.11.2014

13. Chodick G, Porath A, Alapi H, Sella T, Flash S, Wood F, Shalev V. The direct medical cost of cardiovascular diseases, hypertension, diabetes, cancer, pregnancy and female infertility in a large HMO in Israel. Health Policy. 2010;95: 271-6.

14. The Israel Fertility Association (IFA). The ethical approach to futile fertility treatment: Position of the IFA Ethics Committee of the. February 2015. In Hebrew, available at: http://www.ayala.org.il/_Uploads/dbsAttachedFiles/ Ethical_approach_futile_fertility_treatments.pdf.

15. Simonstein F, Mashiach-Eizenberg M, Revel A, Younis JS. Assisted reproduction policies in Israel: a retrospective analysis of in vitro fertilization-embryo transfer. Fertil Steril. 2014;102:1301-6. 